\title{
Morbid obesity: postsurgical predictive factors and prioritization of the waiting list
}

\author{
F. Sabench Pereferrer, M. Hernández González, M. Abelló Salas, J. Domènech Calvet, S. Blanco Blasco \\ and D. del Castillo Déjardin
}

Surgery Department. Faculty of Medicine and Health Sciences. Rovira i Virgili University. San Juan University Hospital. Reus. Tarragona, Spain

\begin{abstract}
Aim: to study a sample of patients with morbid obesity who are on the waiting list for a surgical intervention, to establish various scores of surgical risk (Possum and severity score), and to assess potential criteria for list prioritization.

Design: we calculated physiological and surgical Possum scores for every patient, and analysed comorbidities and other associated factors to calculate the severity score. Likewise, we calculated the predictive rates of morbimortality. Differences between associated comorbidities in body mass index (BMI) were also analyzed. The correlation between Possum score, prediction rates, and severity score were analyzed.

Patients: fifty-two patients on the surgical waiting list in our institution (San Juan University Hospital, Reus) from 26/4/02 to 5/03/04.

Results: the mean qualitative score is significantly higher in the female sex. Invalidating arthropathy and socio-occupational and/or psychiatric criteria are significantly higher in women. There is a significant correlation between the severity score and Possum score. Age does not correlate with any of the variables studied.

Conclusions: possum scores are significantly related to BMI, particularly in terms of morbidity rates. The degree of correlation between the Possum score and the qualitative score tells how useful the latter is to cover other determinant factors in the severity of this condition. Socio-occupational and psychiatric criteria, and invalidating arthropathy are the main variables to be taken into account for postsurgical prediction, and are directly related to BMI degree.
\end{abstract}

Key words: Morbid obesity. Bariatric surgery. Possum scores.

Sabench Pereferrer F, Hernández González M, Abelló Salas M, Domènech Calvet $J$, Blanco Blasco S, del Castillo Déjardin D. Morbid obesity: postsurgical predictive factors and prioritization of the waiting list. Rev Esp Enferm Dig 2005; 97: 161-169.

Recibido: 06-07-04

Aceptado: 28-09-04.

Correspondencia: Daniel del Castillo Déjardin. Servicio de Cirugía. Hospital Universitari Sant Joan. C/ Sant Joan, s/n. 43201 Reus, Tarragona. email:ddelcastillo@grupsagessa.com

\section{INTRODUCTION}

Within the general objectives of all types of surgery, there is a particular interest in obtaining maximal perioperative safety and in maintaining therapy results in the long term. The evolution of bariatric surgery itself allows to recognize the primary risks inherent to every technology, which the introduction of laparoscopy has clearly diminished $(1,2)$.

In the case of bariatric surgery for morbid obesity, the association of numerous comorbidities increases the perioperative risk for this type of surgery, but also cures many of them. Long-term results are not only determined by the effectiveness of the surgical technique itself (3), but also imply and require learning on the part of the patient.

In order to assess the predictive factors that determine increased or reduced effectiveness for a surgical intervention, allowing criteria for the management of the surgical waiting list, we need to deal with the selection of patients from different perspectives. One way of measuring surgical risk, of predicting the morbimortality of a particular technique in a particular patient, is provided by the Possum score (4) (Physiological and Operative Severity Score for the enUmeration of Mortality and Morbidity), which assesses various factors of a physiological nature and other factors inherent in each particular type of surgery (Table I). Possum provides us with a physiological score and an operative score, in addition to predictive rates for morbidity and mortality. Furthermore, this score has been adjusted by means of the Portsmouth equation for mortality prediction (5), in order to prevent this parameter from being overestimated $(6,7)$. Combining the risk of mortality as adjusted by the Portsmouth equation with the risk of postoperative morbidities of the Possum score could be a good way of predicting surgical risk. Even though numerical systems do not fit the overall dimension of a surgical procedure, they can be of use to us 
Table I. POSSUM (Physiologic and Operative Severity Score for the enUmeration of Mortality and Morbidity)

\begin{tabular}{ll}
\hline Physiological score & Surgical score \\
\hline Age & Multiple procedures \\
Glasgow & Total loss of blood \\
Respiratory symptomatology & Neoplastic process \\
Signs of cardiac insufficiency & Type of surgery \\
Urea & Peritoneal soiling \\
Pulse $(p p m)$ & \\
Hb (g/l) & \\
Total leukocyte count & \\
ECG & \\
Potassium (mEql/l) & \\
Sodium (mEq//l) & \\
Systolic blood pressure & \\
Scorable items for each of the Score types (physiological and surgical) of the Pos- \\
sum system
\end{tabular}

as coadjuvants in the process of selecting and prioritizing a surgical series. It is worth noting that the part corresponding to the surgical scoring has been calculated on the basis of certain minimum assumptions prior to surgery, and at all times provides a broad margin in order to prevent the severity of the surgical procedure from being underestimated (8).

It is also necessary to apply a qualitative severity score including the major comorbidities of morbid obesity (9) and other possible determining factors such as age or sex $(10,11)$, socio-occupational and psychiatric factors, or the body mass index itself, in accordance with their distribution in the different levels of morbid obesity (12) (Table II). This qualitative score is based on Kral's obesity severity index (ISO) (13), although this has been adapted to daily clinical practice by introducing parameters such as socio-labour and/or psychiatric criteria and invalidating arthropathy, and by omitting anthropometric indices such as the neck/thigh or waist/hip ratio. All this is of

Table II. Severity score

\begin{tabular}{lc}
\hline Items & Score \\
\hline Time on surgical waiting list & $0.5 / 3$ months \\
Sleep apnea syndrome & 1 \\
$\mathrm{HBP}($ syst $\geq 150 \mathrm{mmHg}$ and/or diast $\geq 90 \mathrm{mmHg}$ ) & 2 \\
Diabetes mellitus & 1 \\
Cardiopathy & 2 \\
Other indications for abdominal surgery & 2 \\
$\mathrm{Smoking}$ & 2 \\
$\mathrm{Hb}>15$ g/l & 1 \\
$\mathrm{pCO}>45 \mathrm{mmHg}$ & 1 \\
History of thromboembolism & 1 \\
Age $\geq 50$ years & 1 \\
Male sex & 1 \\
Invalidating arthropathy & 1 \\
Severe venous insufficiency & 1 \\
History of bariatric surgery & 3 \\
Social-work and/or psychiatric criteria & 1 \\
Classified body mass index (40-49, from $50-59$ and $\geq 60)$ & 2,4 or 6 \\
\hline
\end{tabular}

Items of the modified qualitative severity score of morbidities, and other associated factors and their corresponding score. particular importance in determining the context of each patient in objective terms, and serves as a guide to the professional in order to prevent inadequate coverage of therapeutic needs in this type of patient (14).

The objectives of this work are based on the study of a sample of patients suffering from morbid obesity and on the waiting list for a surgical intervention for their obesity in our hospital, to determine the surgical risk and its comorbidities, and to assess the different order criteria in the inclusion process of said waiting list. We shall do this by introducing the Possum score (physiological and operative) into the field of bariatric surgery, and the predictive postsurgical morbidity and mortality ratios derived from this as determining factors for surgical risk and comorbidities. In turn, we shall introduce the qualitative severity score as a method to assess the major comorbidities associated with the disease and the other possible determining predictive factors such as sex, age, associated social and psychological criteria, and previous bariatric surgery, among others. Subsequently, the relationship between these two scores and their possible usefulness in prioritizing the surgical waiting list will be analyzed.

\section{METHODS}

The study sample is made up of 52 patients suffering from morbid obesity and included on the surgical waiting list in our hospital (San Juan University Hospital in Reus) during the period $26 / 4 / 02$ to $5 / 03 / 04$.

During the process of sample analysis, the following tasks were undertaken in order to determine the possible predictive variables:

-Calculation of the physiological and operative Possum ( $\mathrm{P}$ phys and $\mathrm{P}$ op) for each patient in the sample by means of the scoring established in each of its variables and the analysis of the different comorbidities and other associated factors in each of them, in order to complete the qualitative severity score and give it a numerical score (Tables I and II).

- Calculation of the postoperative predictive rates for morbidity and mortality (morbid R and mortal A) and of the Portsmouth formula for predicting postoperative mortality (M Portsm), in accordance with formulas established for each patient in the sample (Fig. 1).

- Application of the qualitative severity score as a method to assess the major comorbidities associated with the disease and other possible determinant predictive factors, giving it a numerical score.

- Distribution of the quantitative (P phys, $\mathrm{P}$ op, morbid $\mathrm{R}$ and mortal $\mathrm{R}$, age, and severity score) and qualitative variables (obstructive sleep apnea syndrome-SAOS, diabetes mellitus-DM, heart disease, blood hypertension$\mathrm{HBP}$, smoke, $\mathrm{Hb} \geq 15 \mathrm{~g} / \mathrm{l}, \mathrm{pCO}_{2} \geq 45 \mathrm{mmHg}$, history of thromboembolism, invalidating arthropathy, venous insufficiency, previous bariatric surgery, and social and psychiatric criteria) by sex. 
- Analysis of the differences observed according to body mass index (BMI) in the distribution of major associated comorbidities and the aforementioned potential determinant factors.

- Analysis of the distribution of quantitative variables according to the degrees of morbid obesity (BMI of 4049 , of 50-59, and equal to or greater than 60).

-Analysis of the degree of correlation between the Possum score and the predictive rates derived from it, the comorbidities score, and other associated factors.

- To establish the bases for the prioritization of the surgical waiting list in relation to the two types of score, in order to cover the risk factors in the field of bariatric surgery in a sufficiently comprehensive manner, and to assess the possible order criteria in relation to the prediction of postsurgical comorbidities.

To study the distribution of variables and the comparisons of averages, Student's t statistical method, a comparison of averages for independent samples, was used. The statistical analysis of the different qualitative variables was undertaken using the Chi squared method. Pearson's correlation coefficient allowed us to analyze the various correlations in the statistical work.

\section{RESULTS}

\section{Sample characteristics}

The sample has a total of 52 patients $(n=52), 39$ of which are female (75\%) and 13 male (25\%). In surgical terms, $73.1 \%$ are on the waiting list for a gastrojejunal bypass and $26.9 \%$ for a biliopancreatic diversion. Mean age is 44.8 years, and mean BMI is 49.7 , with no significant differences between sexes considered in either case.

In all $30.8 \%$ of patients suffer from loss of sleep, $73.1 \%$ from HBP, $42.3 \%$ from DM, $21.2 \%$ from heart disease, $30.8 \%$ are active smokers, $5.8 \%$ have a history of thromboembolism, $50 \%$ suffer from venous insufficiency of the lower limbs, 25\% suffer from invalidating arthropathy, and $59.6 \%$ display criteria regarding sociolabour and psychological breakdown. Furthermore, $26.9 \%$ have undergone previous bariatric surgery.

The distribution by degree of morbid obesity is $59.6 \%$ for a BMI of $40-49,28.8 \%$ for a BMI of $50-59$, and $11.5 \%$ for a $\mathrm{BMI} \geq 60$. The total average for P phys. is $16.48 \pm 3.67$ points; for $\mathrm{P}$ op it is $17.94 \pm 2.63$ points, for the severity score it is $11.36 \pm 3.34$ points, for morbid $\mathrm{R}$ it is 52.50 , and for mortal $\mathrm{R}$ it is $13.35 \pm 8.77$.

\section{Distribution by sexes}

The qualitative severity score has a significantly higher numerical average in males. Possum physiological values and postoperative morbidity rates are also significantly higher in males. The qualitative score criteria in terms
Table III. Differences in quantitative variables by sex

\begin{tabular}{lcccc}
\hline & $\begin{array}{c}\text { Total } \\
\text { Mean/SD }\end{array}$ & $\begin{array}{c}\text { Women } \\
\text { Mean /SD }\end{array}$ & $\begin{array}{c}\text { Men } \\
\text { Mean } / S D\end{array}$ & Significance \\
& $44.83 / 8.38$ & $44.95 / 8.34$ & $44.46 / 8.83$ & $\mathrm{NS}$ \\
Age & $49.73 / 6.89$ & $49.74 / 7.21$ & $49.70 / 6.11$ & $\mathrm{NS}$ \\
BMI & $11.36 / 3.34$ & $10.74 / 3.30$ & $13.25 / 2.81$ & $<0.05$ \\
Score & $16.48 / 3.97$ & $15.69 / 3.67$ & $18.85 / 4.05$ & $<0.05$ \\
Physiol. Possum & $17.94 / 2.36$ & $17.92 / 2.62$ & $18 / 2.79$ & $\mathrm{NS}$ \\
Surgical Possum & $52.50 / 17.33$ & $49.38 / 17.10$ & $61.83 / 14.99$ & $<0.05$ \\
R morbidity & $13.32 / 8.77$ & $12.25 / 8.99$ & $16.53 / 7.45$ & $\mathrm{NS}$ \\
R mortality & $1.31 / 1.25$ & $1.40 / 1.28$ & $1.02 / 1.13$ & $\mathrm{NS}$ \\
Antiquity WL & & &
\end{tabular}

Distribution of means and SDs for age, BMI (body mass index), and qualitative and Possum scores according to sex, and degree of significance (Student's t) between both sexes.

Table IV. Distribution of qualitative variables by sex

\begin{tabular}{lcccc}
\hline & $\begin{array}{c}\text { Total } \\
(\%)\end{array}$ & $\begin{array}{c}\text { Women } \\
(\%)\end{array}$ & $\begin{array}{c}\text { Men } \\
(\%)\end{array}$ & $\begin{array}{c}\text { Significance } \\
(\mathrm{p})\end{array}$ \\
\hline Sleep apnea & 30.8 & 20.5 & 61.5 & $<0.05$ \\
Blood hypertension & 73.1 & 71.8 & 76.9 & $\mathrm{NS}$ \\
Diabetes mellitus & 42.3 & 41 & 46.2 & $\mathrm{NS}$ \\
Cardiopathy & 21.2 & 12.8 & 46.2 & $<0.05$ \\
$\mathrm{Smoker}$ & 30.8 & 20.5 & 61.5 & $<0.05$ \\
$\mathrm{Hb}>15 \mathrm{~g} / \mathrm{l}$ & 21.2 & 12.8 & 46.2 & $<0.05$ \\
$\mathrm{PCO}_{2}>45 \mathrm{mmHg}$ & 5.8 & 2.6 & 15.4 & $\mathrm{NS}$ \\
History of pulmonary & & & & $\mathrm{NS}$ \\
$\quad$ thromboembolism & 5.8 & 5.1 & 7.7 & $\mathrm{NS}$ \\
Invalidating arthropathy & 25 & 33.3 & 0 & $<0.05$ \\
Venous insufficiency & 50 & 51.3 & 46.2 & $\mathrm{NS}$ \\
History of bariatric surgery & 29.6 & 23.1 & 38.5 & $\mathrm{NS}$ \\
Socio-psychiatric criteria & 59.6 & 69.2 & 30.8 & $<0.05$ \\
\hline
\end{tabular}

Distribution by sex of comorbidities and other factors associated with morbid obesity, and degree of significance $\left(\chi^{2}\right)$ between both sexes.

of presence of heart disease, active smoking, $\mathrm{Hb} \geq 15 \mathrm{~g} / \mathrm{l}$, and sleep loss syndrome are also significantly higher in males. On the other hand, invalidating arthropathy and the presence of socio-labour and/or psychiatric criteria are significantly higher in females (Tables III and IV).

\section{Distribution according to body mass index}

The body mass index values and their variations in relation to the presence or otherwise of the various qualitative items in the score are only significantly different in case of presence of socio-labour and/or psychiatric criteria, and in case of presence of invalidating arthropathy.

One hundred percent of patients with a BMI $>60$ exhibit socio-labour and/or psychiatric criteria versus an average of $54.02 \%$ that also have said criteria but a BMI below 60. In the case of invalidating arthropathy, it is $50 \%$ for a BMI value $>60$, compared to an average of $21.3 \%$ in BMI values below 60 .

A history of bariatric surgery is also accompanied by lower BMI levels; however, in all cases this difference is not statistically significant. 
As far as postsurgical predictive values are concerned, it is worth noting that mortal $\mathrm{R}$ is significantly higher in groups with a $\mathrm{BMI} \geq 50$, specifically in the group with a BMI of 40-49 (mortal. R $10.82 \pm 6.36$ ) and the group with a BMI of 50-59 (mortal. R $17.57 \pm 12.32$ ). In turn, the postsurgical predictive value for morbidity (morbid. $\mathrm{R})$ clearly shows an ascending behavior in relation to the body mass index, this finding being statistically significant $(\mathrm{p}<0.05)$ (morbil. R $47 \pm 15.60$ for the group with a BMI of 40-49, morbil. R $60.06 \pm 19.5$ for a BMI of 5059 , and morbil. R $61.97 \pm 8.5$ for a BMI > 60).

\section{Relationship between the various predictive and severity scores}

We found a significant positive correlation between the qualitative severity score and $\mathrm{P}$ op, $\mathrm{P}$ phys and the morbimortality predictive rates $(\mathrm{p}<0.01)$, this being greater with respect to morbil. $\mathrm{R}(\mathrm{r}=0.58)$ (Table V). Good correlations between the two types of Possum score and predictive rates are to be expected, given their equivalence and the fact that they are calculated from each other.

There is a positive correlation between BMI and the qualitative severity score, as we have seen at the expense of invalidating arthropathy and socio-labour and/or psychiatric criteria. Age does not correlate with any of the variables studied in our series.

\section{DISCUSSION}

The introduction of Possum as a physiological and operative severity score is broadly accepted by general surgery departments (7), and in our case is of major importance since it is significantly related to BMI, particularly the predictive rate of postsurgical morbidities. The body mass index can therefore act as an indirect predic- tive factor of postsurgical complications $(15,16)$.

The degree of correlation between the Possum score and the qualitative score tells how useful the latter is in covering other determining factors for severity in morbid obesity. The presence of socio-labour and psychiatric criteria, and of invalidating arthropathy as items in the qualitative score are the main variables that should be taken into account for postsurgical prediction, and are directly related to BMI degree.

Because of its good correlation with Possum, the adjusted Portsmouth formula is a good alternative, as well as another class of surgical technology, for predicting the rate of postsurgical mortality $(17,18)$.

In our sample, although the male group is smaller in numbers $(n=13)$ to the female group $(n=39)$, males obtained a significantly higher severity score, $\mathrm{P}$ phys and morbid. R. This would imply that if we use this order criteria in the surgical waiting list, the male sex will be prioritized in some way. On the other hand, both invalidating arthropathy and the presence of socio-labour and/or psychiatric criteria are significantly higher in females, with the result that these are the only items in the qualitative score that are significantly related to body mass index. In spite of this, the mean severity score is higher in males, probably because in four items (SAOS, heart disease, $\mathrm{Hb}>15 \mathrm{~g} / \mathrm{l}$, and smokers) the scoring among males is significantly higher. It so happens that none of these items are related to BMI.

All of this leads to think that the possibility of attributing higher scores to invalidating arthropathy and the presence of socio-labour and/or psychiatric criteria could be evaluated. This way, there would probably be a greater correlation between the qualitative score and BMI, and less discrimination towards the female sex if we used this score to prioritize patients in the surgical waiting list.

If we use the predictive rate for morbidity (morbid. R) as a prioritizing criterion in the waiting list, we obtain a greater selection based on body mass index versus the

Table V. Correlations between age, BMI and the various scores

\begin{tabular}{|c|c|c|c|c|c|c|c|}
\hline & Age & $B M I$ & Score & $\begin{array}{c}\text { Physiological } \\
\text { score }\end{array}$ & Surgical score & Morbid R & Mortal $R$ \\
\hline \multicolumn{8}{|l|}{ Age } \\
\hline $\mathrm{BMI}$ & $\begin{array}{c}r=-0.26 \\
n s\end{array}$ & & & & & & \\
\hline Score & $\begin{array}{c}r=0.17 \\
n s\end{array}$ & $\begin{array}{l}r=0.28 \\
p<0.05\end{array}$ & & & & & \\
\hline Physiological score & $\begin{array}{c}r=0.23 \\
n s\end{array}$ & $\begin{array}{c}r=0.18 \\
n s\end{array}$ & $\begin{array}{l}r=0.37 \\
p<0.05\end{array}$ & & & & \\
\hline Surgical score & $\begin{array}{c}r=-0.09 \\
n s\end{array}$ & $\begin{array}{l}r=0.32 \\
p<0.05\end{array}$ & $\begin{array}{l}r=0.38 \\
p<0.05\end{array}$ & $\begin{array}{l}r=-0.23 \\
n s\end{array}$ & & & \\
\hline Morbid R & $\begin{array}{c}r=0.13 \\
\text { ns }\end{array}$ & $\begin{array}{l}r=0.36 \\
p<0.05\end{array}$ & $\begin{array}{l}r=0.58 \\
p<0.001\end{array}$ & $\begin{array}{l}r=0.74 \\
p<0.001\end{array}$ & $\begin{array}{l}r=0.63 \\
p<0.001\end{array}$ & & \\
\hline Mortal R & $\begin{array}{c}r=0.10 \\
n s\end{array}$ & $\begin{array}{c}r=0.21 \\
n s\end{array}$ & $\begin{array}{l}r=0.31 \\
p<0.05\end{array}$ & $\begin{array}{l}r=0.80 \\
p<0.001\end{array}$ & $\begin{array}{l}r=0.31 \\
p<0.05\end{array}$ & $\begin{array}{l}r=0.74 \\
p<0.001\end{array}$ & \\
\hline
\end{tabular}

Coefficient of correlation (Pearson, $r$ ) and degree of significance $(p)$ between age, BMl and the two types of scores (Possum and derived ratios of morbi-mortality, and qualitative severity score). 
use of the qualitative severity score, even though BMI is not involved in the calculation of said rate.

Based on all this, we believe it necessary to establish certain methods and protocols in the field of bariatric surgery in order to analyze all potential parameters of postoperative prediction $(3,19)$. The combination of the Possum score for predicting postsurgical comorbidities, the Possum score as adjusted by means of the Portsmouth equation for predicting mortality rates, and the qualitative severity score could be a good strategy for obtaining a broad margin within total postsurgical prediction. This would allow us to establish prioritizing criteria more efficiently, which is a necessary measure given the rising demand for this type of surgery (20). This is why the design of observational prospective studies is of great use in determining the real efficiency of these protocols, comparing them with postoperative results and providing health professionals with a broad and comprehensive evaluation of morbid obesity and of the fulfilment of postsurgical objectives (21).

\section{REFERENCES}

1. Awad W, Loehnert R. Laparoscopic gastroplasty. Technique and preliminary results in patients with morbid obesity. Rev Esp Enferm Dig 1997; 89: 753-8.

2. Carbajo MA, Martín del Olmo JC, Blanco JI, Cuesta de la Llave C, Martín F, Toledano M, et al. Vertical ring gastroplasty (VRG) in the treatment of the serious clinical obesity. Results and complications. Rev Esp Enferm Dig 1998; 90 (8): 545-52.

3. Kral JG. Selection of patients for anti-obesity surgery. Int J Obes Relat Metab Disord 2001; 25 (Supl. 1): S107-12.

4. Copeland GP, Jones D, Walters M. POSSUM: a scoring system for surgical auditory. Br J Surg 199; 78: 356-60.

5. Prytherch DR, Whiteley MS, Higgins B, Weaver PC, Prout WG, Powell SJ. POSSUM and Portsmouth POSSUM for predicting mortality. Physiological and Operative Severity Score for the enUmeration of Mortality and morbidity. Br J Surg 1998; 85: 1217-20.

6. Yii MK, Ng KJ. Risk-adjusted surgical audit with the POSSUM scoring system in a developing country. Physiological and Operative Severity
Score for the enUmeration of Mortality and morbidity. Br J Surg 2002; 89: 110-3.

7. Jones HJ, de Cossart L. Risk scoring in surgical patients. Br J Surg 1999; 86: 149-57.

8. Alastrué A, García-Luna PP, Formiguera X. Priorización de pacientes en cirugía bariátrica: índice de riesgo. Cir Esp 2004; 75: 225-31.

9. Sugerman HJ, Wolfe LG, Sica DA, Clore JN Diabetes and hypertension in severe obesity and effects of gastric bypass-induced weight loss. Ann Surg 2003; 237: 751-6.

10. Nguyen NT, Rivers R, Wolfe BM. Factors associated with operative outcomes in laparoscopic gastric bypass. J Am Coll Surg 2003; 197: 548-55.

11. Murr MM, Siadati MR, Sarr MG. Results of bariatric surgery for morbid obesity in patients older than 50 years. Obes Surg 1995; 5: 399402.

12. Renquist K. Obesity classification. Obes Surg 1997; 7: 523. 13. Kral JG. Side effects, complications and problems in anty-obesity surgery: introduction of the obesity severity index. Prog Obes Res 1996; 7: 655-61.

13. Kral JG. Side effects, complications and problems in anty-obesity surgery: introduction of the obesity severity index. Prog Obes Res 1996; 7: 655-61

14. Cowan GS Jr, Hiler ML, Buffington C. Criteria for selection of patients for bariatric surgery. Eur J Gastroenterol Hepatol 1999; 11: 69-75.

15. Vieito Amor M, Hernández Iniesta J, Santiveri X, García Ch, Maestre P, Villalonga A, et al. Morbidity and mortality related to anesthesia and surgery in 60 patients treated with bariatric surgery. Rev Esp Anestesiol Reanim 2002; 49: 365-72.

16. Cagigas JC, Escalante $\mathrm{CF}$, Ingelmo A, Hernández Estefania R, Hernanz F, Castillo J, et al. Aplicattion of the Possum system in bariatric surgery. Obes Surg 1999; 9: 279-81.

17. Midwinter MJ, Tytherleigh $M$, Ashley S. Estimation of mortality and morbidity risk in vascular surgery using POSSUM and the Portsmouth predictor equation. Br J Surg 1999; 86: 471-4.

18. Whiteley MS, Prytherch DR, Higgins B, Weaver PC, Prout WG. An evaluation of the POSSUM surgical scoring system. Br J Surg 1996; 83: 812-5.

19. Grundy M, Barondess J, Bellegie NJ, Fromm H. Consensus Development Conference Panel. Gastrointestinal surgery for obese surgery. Ann Intern Med 1991; 115: 956-61.

20. Recomendaciones de la SECO para la práctica de la cirugía bariátrica. Declaración de Salamanca. Cir Esp 2004; 75: 312-4.

21. Obesity and its surgical management. Livingstone EH. Am J Surg 2002; 184: 103-13. 